\title{
Genetic Diversity and Ancestral History of the German Angler and the Red-and-White Dual-Purpose Cattle Breeds Assessed through Pedigree Analysis
}

\author{
Sowah Addo', Jonas Schäler¹, Dirk Hinrichs², Georg Thaller \\ ${ }^{1}$ Institute of Animal Breeding and Husbandry, Christian-Albrechts-University of Kiel, Kiel, Germany \\ ${ }^{2}$ Albrecht Daniel Thaer-Institute of Agricultural and Horticultural Sciences, Humboldt University, Berlin, Germany \\ Email: saddo@tierzucht.uni-kiel.de
}

How to cite this paper: Addo, S., Schäler, J., Hinrichs, D. and Thaller, G. (2017) Genetic Diversity and Ancestral History of the German Angler and the Red-and-White Dual-Purpose Cattle Breeds Assessed through Pedigree Analysis. Agricultural Sciences, 8, 1033-1047.

https://doi.org/10.4236/as.2017.89075

Received: July 29, 2017

Accepted: September 22, 2017

Published: September 25, 2017

Copyright $\odot 2017$ by authors and Scientific Research Publishing Inc. This work is licensed under the Creative Commons Attribution International License (CC BY 4.0).

http://creativecommons.org/licenses/by/4.0/

\begin{abstract}
Local cattle breeds continue to decline in numbers partly due to the use of high performing breeds in advanced production systems where genetic material of elite animals is widely spread. The objective of this study was to assess the within and across breed genetic diversity of the Angler and Red-andWhite dual-purpose (DP) cattle breeds applying different inbreeding concepts. Classical and ancestral inbreeding coefficients were computed from pedigree data using the gene dropping method. Effective population size was calculated based on the increase of classical inbreeding, and based on ancestral inbreeding to obtain what was termed as ancestral effective population size. Furthermore, the effective number of founders and ancestors were computed to assess the disequilibrium of founder contribution in the reference populations. The analyses were performed separately for each breed and for a combined dataset. The Angler pedigree was more complete $(88 \%)$ in the first parental generation but completeness declined with increasing pedigree depth. Average classical inbreeding coefficients of inbred individuals were $2.19 \%, 1.94 \%$ and $2.07 \%$, while average Ballou's ancestral inbreeding coefficients were $3.69 \%, 1.39 \%$ and $2.21 \%$ for the Angler, Red-and-White DP and the combined breed pedigree analyses, respectively. Ancestral history coefficient is a novel coefficient and its estimates were similar and strongly correlated to Ballou's coefficients $(r=0.99, p<0.001)$. The effective population size estimates ranged from 156 to 170 for the classical inbreeding based method, and as low as from 50 to 54 for the ancestral history coefficient based method. The effective number of founders and ancestors ranged from 310 to 532, and
\end{abstract}


90 to 189, respectively. Our results show that the Red Holstein breed is a key progenitor of the breed populations under study. This highlights cross breeding schemes introduced to improve the milk trait performance of the Angler and Red-and-White DP breeds some decades ago.

\section{Keywords}

Ancestral Inbreeding, Effective Population Size, Pedigree Analysis, Genetic Diversity, Local Cattle

\section{Introduction}

Angler (RVA) and Red-and-White DP (RDN) cattle are local breeds of German origin. Both breeds have small populations predominantly found in the Northern part of the country. Planned breeding of RVA dates back to 1838, however, the organisation of a central herdbook and official milk recording began in 1879 and 1902, respectively [1]. The RVA breed has been used to improve many local red breeds of central and eastern European countries as well as in the Baltic countries [2], [3]. Lactation yield of RVA cows is about $7500 \mathrm{~kg}$ with approximately $3.5 \%$ protein and $5 \%$ fat. Systemic breeding of RDN cattle on the other hand started in 1885 and from 1992, a pedigree of the breed typically has a maximum of $25 \%$ Red Holstein genes [4]. To maintain large populations for bull testing, there were exchanges of bulls between the RDN population in Germany and the Meuse-Rhine-Yssel (MRY) population in The Netherlands [5]. German RDN bulls were also used in Belgium to improve the native Red-and-White breed after the merging of provincial herd books into a single national herdbook in 1970 [6]. RDN cows produce on average $7000 \mathrm{~kg}$ milk per lactation with approximately $3.5 \%$ protein and $4 \%$ fat.

Available data from the German Federal Office for Agriculture and Food indicate a gradual decline in herdbook number of RVA and RDN bulls and cows over the past two decades [7]. During the same period, however, the number of herdbook cows increased markedly for the high performing German Holstein breed. Based on effective population size $\left(N_{e}\right)$, the German National Committee on Animal Genetic Resources (AnGR) classified RVA as a monitoring population $\left(200<N_{e} \leq 1000\right)$ and $\mathrm{RDN}$ as a conservation population $\left(N_{e} \leq 200\right)$ [7]. The $N_{e}$ values for the categorisation were calculated based on herdbook number of male and female animals. This estimation procedure is generally useful in the absence of pedigree data. With the availability of pedigree information, pedigree analysis can offer a better understanding of the population structure and trends in inbreeding of these breeds. In dairy cattle, pedigree analysis has often been used in genetic diversity studies [8], [9], and in assessing the effect of inbreeding on differing phenotypic traits [10] [11] [12] [13]. Apart from a few studies [10] [13], most pedigree analyses involving dairy cattle were focused on classical in- 
breeding without considering the age of inbreeding. Meanwhile, ancestral inbreeding concepts [14], [15] are well established. In a recent publication, Ballou's and Kalinowski's ancestral inbreeding coefficients were redefined [16], and the authors introduced the ancestral history coefficient $\left(\mathrm{A}_{\mathrm{HC}}\right)$ defined as the number that tells how many times during pedigree segregation (gene dropping) a randomly taken allele has been in IBD status.

In the current study, we performed both within and across breed diversity assessment by calculating classical inbreeding coefficients, ancestral inbreeding coefficients according to Ballou [15] and as suggested by Kalinowski [14], and $\mathrm{A}_{\mathrm{HC}}$ for the RVA and RDN cattle breeds. Furthermore, we calculated the effective population size, effective number of founders and of ancestors, and investigated the contribution of key ancestors to inbreeding.

\section{Materials and Methods}

\subsection{Pedigree Information}

Pedigree data for RVA and RDN span the period between 1906 and 2016 and were obtained from the official computation centre responsible for breeding value estimation (Vereinigte Informationssysteme Tierhaltung w. V., Verden, Germany). The RVA dataset consisted of 93,078 animals, including 10,481 bulls and 82,597 cows. A total of 184,358 animals including 16,068 bulls and 168,290 cows formed the RDN pedigree dataset. For both breeds, there has been some form of introgression of genetic material from other conventional breeds including the German Black-and-White Holstein (SBT), German Red-and-White Holstein (RBT), Holstein from North America (HOL), Jersey (JER), Braunvieh (BV), Fleckvieh (FV) and Scandinavian Red cattle. Breeds other than RVA and RDN were therefore present in both datasets, and consequently, 12,709 animals were common to both pedigrees. The completeness of pedigree [17] was computed for all animals to ascertain the proportion of known ancestors per generation. Additionally, the number of equivalent complete generations known in the pedigree was computed as the sum over all known ancestors of the term $(1 / 2)^{\mathrm{n}}$, where $n$ is the number of generations separating the individual from each known ancestor [18].

\subsection{Data Processing, Analysis and Softwares}

Using SAS software (SAS 9.4, SAS Institute Cary, NC, USA), we recoded the animal identification numbers (Ids) in the raw pedigree file from 15 digits to 14 digits, the maximum number required by PEDIG software [19]. PEDIG software was used for the extraction, verification, sequential recoding of the pedigrees, and for the calculation of classical inbreeding coefficients for all animals. The raw pedigree data were also recoded sequentially using the $\mathrm{R}$ software package QTLRel [20], and in the process mismatches regarding the sex of animals were corrected. The GRAIN software package [16] was applied for the computation of 
ancestral inbreeding coefficients. To describe possible disequilibrium of founder contribution to the reference population (RP, i.e. animals with both parents known), ENDOG v4.8 [21] was used to compute parameters derived from the probability of gene origin. Pedigree analysis was carried out separately for each breed, and for the combined data (RVA_RDN), the latter involving 264,727 different individuals. In all three cases, animals with no known parents in the pedigree data were considered as founders and assumed unrelated.

\subsection{Classical and Ancestral Inbreeding}

The classical individual inbreeding coefficient $(F)$, defined as the probability of an individual having two identical alleles by descent, was calculated following [22] and averaged over all as well as inbred animals. We also calculated classical inbreeding coefficients together with ancestral inbreeding coefficient according to Ballou [15] and as suggested by Kalinowski [14], and $\mathrm{A}_{\mathrm{HC}}$ [16] using a modified version of gene dropping [23], [24] with $10^{6}$ replications. Originally, Ballou's ancestral inbreeding coefficient ( $\mathrm{Fa} \_\mathrm{Bal}$ ) refers to the cumulative proportion of an individual's genome that has been previously exposed to inbreeding in its ancestors. Without changing the original meaning of the parameter, $\mathrm{Fa}$ _Bal was recently defined as the probability that any allele in an individual has been autozygous (IBD) in previous generations at least once [16]. Kalinowski's approach to ancestral inbreeding gives a narrower meaning of the parameter, and is defined as the probability that any allele in an individual is currently autozygous (IBD) and has been autozygous in previous generations at least once. The ancestral history coefficient is quite novel and by definition, tells how many times during pedigree segregation a randomly taken allele has been in IBD status [16].

\subsection{Effective Population Size}

Defined as the number of individuals in an ideal population that would give rise to the same rate of inbreeding as observed in the actual breeding population [25], $N_{e}$ was computed by first, calculating the rate of inbreeding as the regression coefficient $(b)$ of the classical inbreeding coefficient $(F)$ on the equivalent complete generation [21]. Secondly, $N_{e}$ values were obtained using Equation (1) below.

$$
N_{e}=1 / 2 b
$$

Additionally, we applied the same estimation procedure in the calculation of what we termed as ancestral effective population size, which can be defined as the size of a population as reflected by its rate of ancestral inbreeding. In this regard, three values being $N_{e} B a l, N_{e \_} K a l$ and $N_{e} A_{H C}$ were distinguishable.

\subsection{Probability of Gene Origin Based Parameters}

The effective number of founders $\left(f_{e}\right)$ and effective number of ancestors $\left(f_{a}\right)$ best describe the unbalanced representation of founder contributions in a refer- 
ence population. Parameter $f_{e}$ defines the number of equally contributing founders that would be expected to produce the same genetic diversity as in the population under study [26]. Except in situations where each founder contributes the same to a reference population, $f_{e}$ is always smaller than the actual number of founders. Calculation of $f_{e}$ follows Equation (2) below,

$$
f_{e}=1 / \sum_{k=1}^{f} q_{k}^{2}
$$

where $q_{k}$ is the probability that a gene randomly sampled in the population originates from founder $k$, and $f$ is the total number of founders [27]. Parameter $f_{a}$ on the other hand refers to the minimum number of ancestors, not necessarily founders, explaining the complete genetic diversity of a population [27] and can be computed using Equation (3).

$$
f_{a}=1 / \sum_{j=1}^{a} q_{j}^{2}
$$

In Equation (3), $q_{j}$ represents the marginal genetic contribution of ancestor $j$, i.e. the genetic contribution made by an ancestor that is not explained by previously chosen ancestors, and $a$ is the total number of ancestors considered. To calculate marginal genetic contributions, the first major ancestor was found based on its raw genetic contribution (i.e. $q_{k}=q_{j}$ ) following an iterative procedure. Next, the genetic contribution of the $n^{\text {th }}$ major ancestor was calculated conditional on the genetic contribution of the $n-1$ already chosen ancestors. Reference [27] presents a detailed algorithm to compute marginal genetic contribution. Therefore, parameter $f_{a}$ accounts for the losses of genetic variability which result from the unbalanced use of reproductive individuals producing a bottleneck. Furthermore, the ratio of the two parameters (i.e. $f_{a} / f_{e}$ ) actually reflects the role of bottleneck in the development of the population. Values close to one indicate the absence of a bottleneck.

\section{Results and Discussion}

\subsection{Completeness of Pedigree}

Figure 1 shows the completeness of pedigree across parental generations for the RVA, RDN and the RVA_RDN datasets. Completeness of the RVA pedigree was about $90 \%$ and higher than that of the $\mathrm{RDN}(64 \%)$ in the first parental generation. For the same parental generation, pedigree completeness was intermediate when the two pedigrees were combined (RVA_RDN). The proportion of known ancestors decreased quite steadily with increasing pedigree depth such that, completeness was below $50 \%, 20 \%$ and $30 \%$ at the seventh parental generation for RVA, RDN and RVA_RDN, respectively. Beyond the thirteenth parental generation, completeness was close to zero in all three cases. Published estimates of pedigree completeness level for cattle vary a lot. It ranges from $99 \%$ to below $10 \%$ in recent and founder generations, respectively [28] [29] [30]. Mean values for the number of known equivalent complete generations were 5.59, 2.7 and 


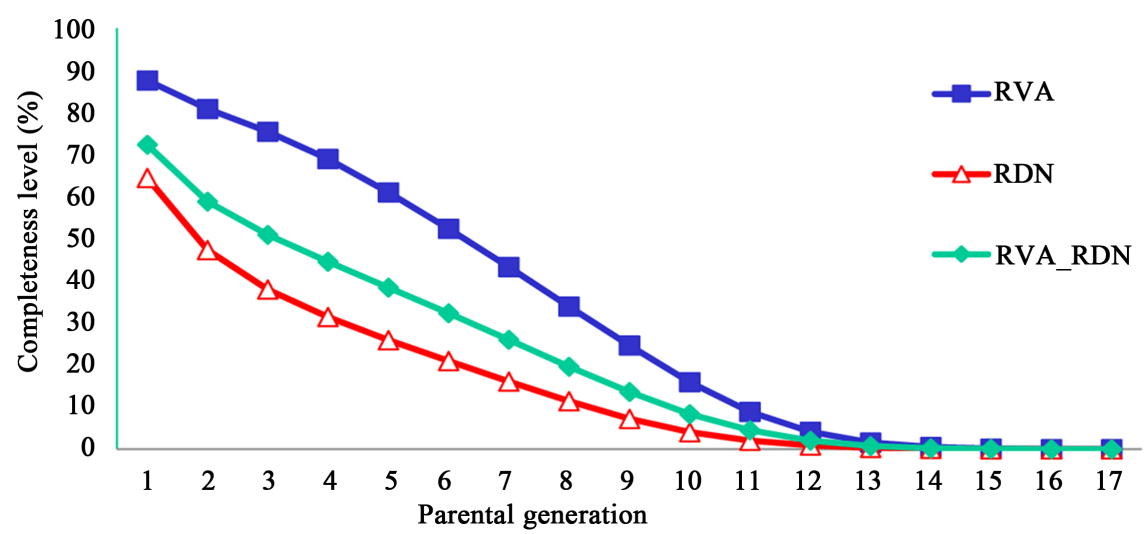

Figure 1. Pedigree completeness indicating the percentage of known ancestors per parental generation, computed for the RVA, RDN and RVA_RDN pedigrees (Parental generation 1 represents parents, 2 represents grandparents, etc.).

3.73 for RVA, RDN and RVA_RDN, respectively, and consistent with the ranking of the three scenarios based on the trends in pedigree completeness across parental generations. The equivalent complete generation is an appropriate criterion to characterise pedigrees [18]. The estimated mean equivalent complete generation for RVA in this study was higher than the estimate for French Holstein (4.75) [18] but lower than that reported for German Holstein cows (6.15) [9].

Similar to the results of previous studies, there is a general trend of decreasing pedigree completeness with increasing pedigree depth. Pedigree recording in the study populations started over a century ago and at a time when little was known about planned breeding. Recognition of breed importance and improvements achieved in breeding over the years are contributing factors to the observed increase in data recording from founder to recent generations. Incompleteness of pedigrees in this study implies a caution about the overreliance on our data for inbreeding estimation. It was demonstrated that with only $10 \%$ of unknown pedigree, inbreeding is strongly underestimated [27].

\subsection{Different Inbreeding Coefficients}

The numbers of inbred individuals were 59,000, 39,477 and 95,343 representing $64 \%, 21 \%$ and $36 \%$ for RVA, RDN and RVA_RDN, respectively. The percentage of inbred individuals was low for the RDN pedigree and this is due to the inability of the pedigree data to fully capture the relationships between all animal as discussed previously. Table 1 summarises the mean values of classical inbreeding coefficients for all and inbred individuals, Ballou's and Kalinowski's ancestral inbreeding coefficients, and ancestral history coefficients calculated for the three different pedigree datasets. Generally, the inbreeding estimates were higher for the RVA breed and intermediate for the combined breed analysis. Average classical inbreeding coefficient of inbred individuals in this study ranged from 1.94 to 2.19 and were lower than the estimate for German Holstein dairy cattle 
Table 1. Average classical inbreeding coefficients and estimates of average ancestral inbreeding coefficients computed for the RVA, RDN and RVA_RDN pedigrees.

\begin{tabular}{cccc}
\hline Item & RVA (\%) & RDN (\%) & RVA_RDN (\%) \\
\hline$F$ for all animals & 1.39 & 0.41 & 0.75 \\
$F$ for inbred animals & 2.19 & 1.94 & 2.07 \\
$F_{-}$Bal & 3.69 & 1.39 & 2.21 \\
$F_{-}$Kal & 0.16 & 0.05 & 0.09 \\
$\mathrm{~A}_{\text {HC }}$ & 3.94 & 1.49 & 2.37 \\
\hline
\end{tabular}

(3.25\%) [13]. More interesting are the changes in inbreeding over time for all individuals in each pedigree dataset. As shown in Figure 2, the level of inbreeding started rising steadily only after the 1940s. Before this period, only a few animals existed in all pedigrees as most animals were born after the 1960s. From the 1960s onwards, inbreeding levels increased markedly and continuously in all three cases but dropped for the RDN breed after the 1990s. Average inbreeding coefficient usually increases over time especially in small and closed populations where the mating of related individuals is unavoidable. Comparatively, the RVA breed has a smaller population size, which may have accounted for the high and continuous increase of inbreeding rate. There may have been an intervention to curb the increase of inbreeding for the RDN breed population from the 1990s, but we do not have adequate information to substantiate this.

Knowing the population level inbreeding rate alone is not enough, rather, the effect of inbreeding as manifested in the reduction in individual's performance per unit increase in inbreeding coefficient (i.e. inbreeding depression). Ballou's concept of ancestral inbreeding proposes a measure that tells which individuals or population harbour fewer detrimental genes. Thus, higher values of the parameter indicate the likelihood of an individual having fewer detrimental genes. Following this concept, it can merely be said that the RVA breed population has endured high inbreeding at the ancestral level $\left(F_{-} \mathrm{Bal}=3.69 \%\right)$ and is probably prone to fewer incidents of inbreeding depression. The mean estimates for $F_{-} \mathrm{Kal}$ were much lower, i.e. $0.16 \%, 0.05 \%$ and $0.09 \%$ for RVA, RDN and RVA_RDN, respectively. By definition, $F_{-}$Kal deals with alleles which are homozygous because they have met in the past, and only includes the ancestral inbreeding of relationship. This means that unlike $F_{-} \mathrm{Bal}, F_{-} \mathrm{Kal}$ for an individual remains zero when its classical inbreeding coefficient is zero. Note, that our analysis did not include the second component of the parameter that deals with new inbreeding. To our knowledge, the results on $\mathrm{A}_{\mathrm{HC}}$ in this study represent one of the first tests of this coefficient using real data. Estimates of $\mathrm{A}_{\mathrm{HC}}$ were high i.e. $3.94 \%, 1.49 \%$ and $2.37 \%$ for RVA, RDN and RVA_RDN, respectively, and very similar to the estimates of $F_{-} \mathrm{Bal}$. The advantage of $\mathrm{A}_{\mathrm{HC}}$ is that it offers an appropriate measure of inbreeding when selection against deleterious recessive alleles is less than fully efficient. The correlation between the different inbreeding coefficients are 


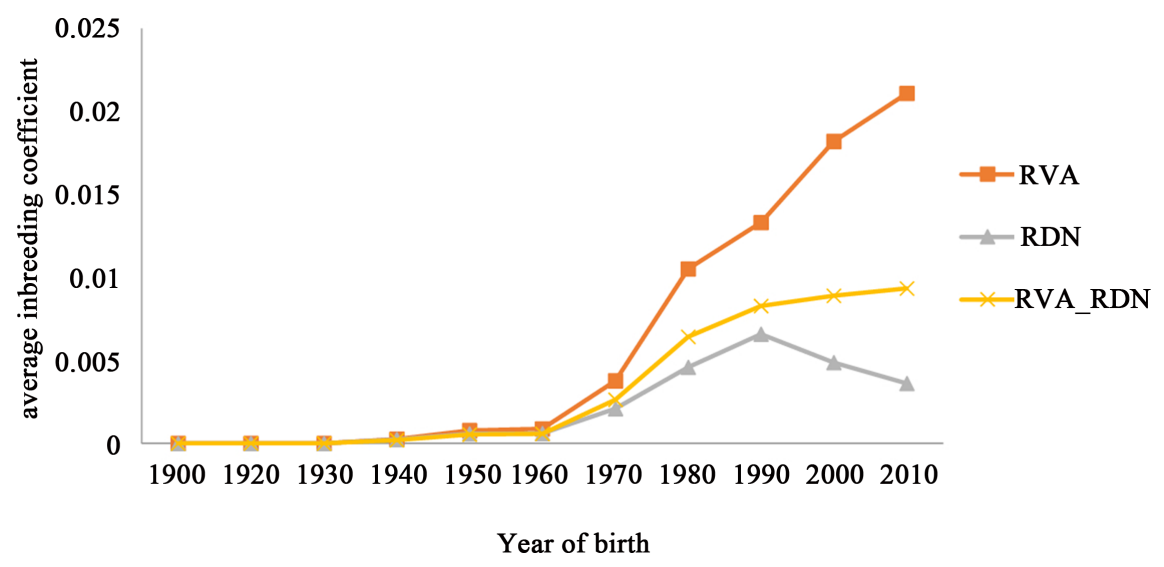

Figure 2. Changes in the per-decade average inbreeding coefficients for the RVA, RDN and RVA_RDN complete pedigrees.

presented in Table 2. Similar estimates of classical inbreeding coefficient were obtained for the computation following [22] ( $F_{-}$Meuw) and by the use of gene dropping method as implemented using GRAIN ( $F$ _Gendrop). Correlation between $F_{-}$Meuw and $F_{-}$Gendrop was near perfect $(r=0.99, p<0.001)$ for both; the analysis involving the complete pedigree (above diagonal) and for the calculation using only inbred individuals (below diagonal). This served as a check of accuracy for our gene dropping procedure used in computing all ancestral inbreeding coefficients. For the complete data, $\mathrm{A}_{\mathrm{HC}}$ and $F_{-} \mathrm{Bal}$ were almost identical $(r=0.99, p<0.001)$, however, the correlation between either of the two coefficients and the classical inbreeding coefficient was intermediate $(r=0.50, p<$ 0.001). The situation was the same for inbred individuals but the estimates were slightly lower. Correlations between classical inbreeding coefficient and $\mathrm{Fa} \_\mathrm{Bal}$ calculated for inbred animals in the current study were slightly lower than those found in previous studies; (0.61) [13] and (0.36 - 0.40) [10]. The correlations between classical inbreeding coefficient and $\mathrm{Fa}_{-} \mathrm{Kal}$ were also slightly lower in our study than in the afore-mentioned studies. Between $\mathrm{Fa}$ _Bal and $\mathrm{Fa}_{-} \mathrm{Kal}$, the correlation estimates in the current study were lower than those by [13] (0.89) but higher than those found by [10] (0.28 to 0.38 ). Based on their obtained weak correlation between $\mathrm{Fa} \_\mathrm{Bal}$ and $\mathrm{Fa} \_\mathrm{Kal}$, the authors [10] argued that the two coefficients measure different population statistics. However, our results and those of the other authors [13] suggest some kind of relationship between the two coefficients. Differences in correlation estimates between the different inbreeding coefficients as reported by different authors are expected since populations differ in pedigree structure.

\subsection{Effective Population Size}

Estimates of effective population size are given in Table 3. The effective population size computed based on the increase of classical inbreeding coefficient was higher for RDN (170) than for RVA (156). Note, that the RDN pedigree recorded 
Table 2. Correlations between different inbreeding coefficients computed for all animals in the combined pedigree $(\mathrm{n}=264,727$, above diagonal elements.) and for inbred animals ( $\mathrm{n}=95,343$, below diagonal elements.) with $p$ value $<0.001$ in all cases.

\begin{tabular}{cccccc}
\hline Parameter & $F_{-}$Meuw & $F_{-}$Gendrop & $F a_{-}$Bal & $\mathrm{A}_{\mathrm{HC}}$ & $F a_{-}$Kal \\
\hline$F_{-}$Meuw & - & 0.999 & 0.506 & 0.502 & 0.748 \\
$F \_$Gendrop & 0.999 & - & 0.506 & 0.502 & 0.748 \\
$F$ a_Bal $_{-}$ & 0.264 & 0.264 & - & 0.998 & 0.658 \\
$\mathrm{~A}_{\mathrm{HC}}$ & 0.266 & 0.266 & 0.997 & - & 0.669 \\
$F$ F_Kal & 0.679 & 0.679 & 0.634 & 0.648 & - \\
\hline
\end{tabular}

Table 3. Estimates of effective population size computed based on classical and ancestral inbreeding concepts for the RVA, RDN and RVA_RDN datasets.

\begin{tabular}{cccc}
\hline Parameter & RVA & RDN & RVA_RDN \\
\hline$N_{e}$ & 156 & 170 & 161 \\
$N_{e \_} B a l$ & 54 & 59 & 58 \\
$N_{e \_}$Kal & 1040 & 1186 & 1160 \\
$N_{e \_} A_{H C}$ & 50 & 54 & 53 \\
\hline
\end{tabular}

the lowest average inbreeding coefficient but also the poorest pedigree quality. Here, effective population size values were estimated by regressing the individual inbreeding coefficients on the equivalent complete generations traced and considering the regression coefficient as the rate of inbreeding. The same procedure was applied to the individual estimates of $F \mathrm{a} \_\mathrm{Bal}, F{ }_{-} \mathrm{Kal}$ and $\mathrm{A}_{\mathrm{HC}}$ to calculate for the first time ancestral effective population size which we defined as the size of a population as reflected by its rate of ancestral inbreeding. The ancestral effective population size estimates based on $F \_B a l\left(N_{\varrho} B a l\right)$ and that based on $\mathrm{A}_{\mathrm{HC}}\left(N_{e} A_{H C}\right)$ were similar and ranged from 50 to 59 animals for all data considerations. Estimates of ancestral effective population size based on $\mathrm{Fa} \_\mathrm{Kal}$ $\left(N_{e-} K a\right)$ on the other hand, were unrealistically high and above 1000 animals. Nevertheless, these high estimates are not surprising since Fa_Kal considers only "old" inbreeding. Applying different computation methods [30], pedigree based $N_{e}$ values ranging from 47 to 167 animals were reported for the Rotes Hoehenvieh cattle breed. The estimated $N_{e}$ values in the current study are higher than the threshold number of 50 animals [31], and between 50 and 100 animals [32], below which the fitness of a population is expected to decrease.

\subsection{Founder and Ancestor Contributions}

The parameters derived from the probability of gene origin account for the unbalanced use of founders in a pedigree and unlike $N_{e}$, are less affected by pedigree errors [27]. In Table 4, the results of the parameters derived from the probability of gene origin are given. Additionally, statistics on the number of animals that formed the reference and base populations are given. The RDN 
Table 4. Number of animals in the reference and base populations, and the effective number of founders and ancestors computed from the probability of gene origin for the RVA, RDN and RVA_RDN pedigrees.

\begin{tabular}{cccc}
\hline Item & RVA & RDN & RVA_RDN \\
\hline Total number of animals (N) & 93,078 & 184,358 & 264,727 \\
Animals with both parents known (RP) & 76,520 & 73,749 & 142,240 \\
Base population (N - RP) & 16,558 & 110,609 & 122,487 \\
Ancestors contributing to reference population & 10,059 & 24,101 & 30,911 \\
Effective number of founders & 310 & 519 & 532 \\
Effective number of ancestors & 90 & 189 & 159 \\
$f_{a} / f_{e}$ & 0.29 & 0.36 & 0.30
\end{tabular}

pedigree had a slightly lower RP number $(73,749)$ although it has the highest total number of animals. A total of 10,059, 24,101 and 30,911 ancestors, some of which were not founders contributed to the RVA, RDN and RVA_RDN reference populations, respectively.

The $f_{e}$ values obtained were 310 (RVA), 519 (RDN) and 532 (RVA_RDN). Published $f_{e}$ values for other cattle breeds range from 40 to 649 animals [28], [33], [34]. These values depended on the actual number of founders making it interesting to interpret $f_{e}$ in relation to the actual number of founder rather than a simple comparison of absolute values across studies. Compared to the actual number of founders, the estimated $f_{e}$ values in the current study suggest an unbalanced genetic contribution in the founder population of all three cases. A simple offspring analysis of our data revealed an excessive use of some individuals, especially males as parents. An individual in the Angler pedigree for instance, sired 1485 offspring (results not shown). Meanwhile, the obtained $f_{a}$ values show that only 90,189 and 159 animals explained the complete genetic diversity in the RVA, RDN and RVA_RDN reference gene pools, respectively. In all three cases, the $f_{a} / f_{e}$ ratio indicates the occurrence of a genetic bottleneck since the foundation of the population, and the RVA population is the most impacted. The use of artificial insemination in these breeds is a contributing factor to the observed genetic bottleneck.

The marginal genetic contribution of the top 10 ancestors to the RVA, RDN and RVA_RDN reference populations are given in Table 5. Total genetic contribution of the top 10 ancestors were $26.3 \%, 18 \%$ and $19 \%$ for RVA, RDN and RVA_RDN, respectively. These ancestors either had many offspring or did contribute enormously through their famous offspring, as was the case for the only female ancestor (ID = 840000000005304) whose two sons sired 226 and $15 \mathrm{im}$ mediate progenies. Interestingly, some of the top ancestors (see superscript $a, b$ and $c$ ) were common to both the RVA and RDN pedigrees. These ancestors and some others (superscript $d, e$, and $f$ under RVA, and $g$ under RDN) also appear in the combined breed analysis as major ancestors. The current popula- 
Table 5. Marginal genetic contribution of the top 10 ancestors to the RVA, RDN and RVA_RDN reference populations given by the sex of individual, birth year, breed type and number of offspring.

\begin{tabular}{|c|c|c|c|c|c|}
\hline Ancestor ID & Sex & Birth Year & Breed Type & $\begin{array}{c}\text { Marginal } \\
\text { contribution }\end{array}$ & Offspring \\
\hline \multicolumn{6}{|l|}{$R V A$} \\
\hline 840000001842371 & Male & 1980 & Red \& White Holstein & 0.045423 & 167 \\
\hline $840000001629391^{\mathrm{a}}$ & Male & 1972 & Red \& White Holstein & 0.029506 & 135 \\
\hline $276000102168990^{\mathrm{d}}$ & Male & 1974 & Angler & 0.027598 & 244 \\
\hline $276002240018965^{\mathrm{e}}$ & Male & 1966 & Angler & 0.027072 & 328 \\
\hline $840000001491007^{\mathrm{b}}$ & Male & 1965 & Red \& White Holstein & 0.025572 & 231 \\
\hline $752000000093907^{\mathrm{f}}$ & Male & 1990 & Angler & 0.024679 & 184 \\
\hline $840000001427381^{c}$ & Male & 1962 & Red \& White Holstein & 0.023268 & 93 \\
\hline 000008400028756 & Male & 1963 & Angler & 0.021919 & 19 \\
\hline 528000775157228 & Male & 1991 & Red \& White Holstein & 0.019265 & 147 \\
\hline 276000102142217 & Male & 1970 & Angler & 0.018949 & 605 \\
\hline \multicolumn{6}{|l|}{$R D N$} \\
\hline $840000001629391^{\mathrm{a}}$ & Male & 1972 & Red \& White Holstein & 0.031539 & 245 \\
\hline $840000001491007^{\mathrm{b}}$ & Male & 1965 & Red \& White Holstein & 0.025185 & 323 \\
\hline 528000000355040 & Male & 1973 & Red \& White (RDN) & 0.018695 & 166 \\
\hline $124000000267150^{\mathrm{g}}$ & Male & 1958 & Red \& White Holstein & 0.018484 & 59 \\
\hline 528000000338535 & Male & 1971 & Red \& White Holstein & 0.017550 & 47 \\
\hline $840000001427381^{c}$ & Male & 1962 & Red \& White Holstein & 0.017217 & 94 \\
\hline 840000001189870 & Male & 1952 & Red \& White Holstein & 0.014265 & 90 \\
\hline 000009002053500 & Male & 1966 & Red \& White Holstein & 0.013015 & 349 \\
\hline 528000951276374 & Male & 1982 & Red \& White (RDN) & 0.011961 & 25 \\
\hline 000009002037187 & Male & 1965 & Red \& White Holstein & 0.011538 & 116 \\
\hline \multicolumn{6}{|l|}{$R V A \_R D N$} \\
\hline $840000001629391^{a}$ & Male & 1972 & Red \& White Holstein & 0.037133 & 279 \\
\hline 840000001620273 & Male & 1972 & Red \& White Holstein & 0.025723 & 24 \\
\hline $840000001491007^{\mathrm{b}}$ & Male & 1965 & Red \& White Holstein & 0.024239 & 377 \\
\hline $840000001427381^{c}$ & Male & 1962 & Red \& White Holstein & 0.019417 & 114 \\
\hline $276000102168990^{\mathrm{d}}$ & Male & 1974 & Angler & 0.014904 & 245 \\
\hline $276002240018965^{\mathrm{e}}$ & Male & 1966 & Angler & 0.014614 & 329 \\
\hline $124000000267150^{\mathrm{g}}$ & Male & 1958 & Red \& White Holstein & 0.014474 & 61 \\
\hline $752000000093907^{\mathrm{f}}$ & Male & 1990 & Angler & 0.013290 & 184 \\
\hline 840000000005304 & Female & 1973 & Red \& White Holstein & 0.012795 & 2 \\
\hline 840000001189870 & Male & 1952 & Red \& White Holstein & 0.012364 & 92 \\
\hline
\end{tabular}

${ }^{a-g}$ Ancestor IDs with the same superscript indicate the same animal appearing in the different pedigree datasets (Ancestors were selected based on marginal contribution calculated following [27]). 
tion of Angler and Red-and-White DP cattle breeds are genetically not distinct. In fact, they share common ancestors some of which can be traced back to as early as 1965. Most striking is the high genetic contribution of the Red-and-White Holstein breed to the breed populations under study. For the Red-and-White dual purpose breed, it has been established that a pedigree of the breed has a maximum of $25 \%$ Red Holstein genes [4]. These revelations highlight crossbreeding schemes established to improve the performance of local cattle breeds some decades ago.

\section{Conclusion}

Analysing the Angler and Red-and-White dual-purpose local cattle pedigrees has shed some light on the population structure of these breeds in Germany. The current study demonstrates that Ballou's approach to estimate ancestral inbreeding and the novel ancestral history coefficients are similar approaches that produce comparable results. Besides, these coefficients provide avenue to calculate effective population size at the ancestral level. The effective population size of the breeds did not raise concern, however, due to incompleteness of the pedigree data used, consideration of the parameters derived from the probability of gene origin was extremely necessary in characterising the genetic diversity within the populations. For both breeds, the reference populations were raised from founder or ancestor groups, within which genetic contributions were typically unbalanced, male animals being favoured. Consequently, only a few animals explained the complete genetic diversity in the population under study. The Red Holstein breed is a key progenitor of the current Angler and Red-and-White dual-purpose cattle populations in Germany. Based on the high genetic contribution of key ancestors belonging to other breeds, we recommend an extensive investigation of foreign blood percentage in both breeds.

\section{Acknowledgements}

This work was conducted as part of the research activities of the operational group, "Animal Genetic Resources" that operates under the auspices of the Agricultural European Innovation Partnership (EIP-AGRI) project. The authors are thankful to the European Commission for providing funds for the project. Personnel at the "Vereinigte Informationssysteme Tierhaltung" in Lower Saxony are also acknowledged for the provision of data and their relentless efforts in answering questions about the datasets used.

\section{References}

[1] Thompson, D.M. (1986) A Study of Red Dairy Cattle Breeds in the United Kingdom and Europe. Royal Agricultural Society of Victoria, Royal Showgrounds, Acsor Vale. http://www.nuffield.com.au/report/1980-89/d.m-thompson-1986-report.pdf

[2] Felius, M., Beerling, M.L., Buchanan, D.S., Theunissen, B., Koolmees, P.A. and Lenstra, J.A. (2014) On the History of Cattle Genetic Resources. Diversity, 6, 705-750. 
https://doi.org/10.3390/d6040705

[3] Adamczyk, K., Felenczak, A., Jamrozy, J., Szarek, J. and Bulla, J. (2008) Conservation of Polish Red Cattle. Slovak Journal of Animal Science, 41, 72-76.

[4] Andresen, U., Bartjen, A. and Kaske, M. (2014) German Red and White Coloured Dual Purpose an Alternative for a Sustainable Milk Production? Tieraerztliche Umschau, 69, 537-542.

[5] CGN (2009) MRIJ Breed Assessment. EU GENRES 870/04 Project EURECA. Centre for Genetic Resources, the Netherlands (CGN) of Wageningen UR.

http://www.regionalcattlebreeds.eu/publications/documents/5384_mrij\%20koeien_ engels.pdf

[6] Bay, E., Colinet, F. and Gengler, N. (2010) Dual Purpose Red and White. EU GENRES 870/04 project EURECA. Gembloux Agro-Bio Tech. Belgium.

http://www.regionalcattlebreeds.eu/country_and_breed_information/belgium/docu ments/Dual\%20Purpose\%20Red\%20and\%20White.pdf

[7] TGRDEU (2016) Zentrale Dokumentation Tiergenetischer Ressourcen in Deutschland, Bundesanstal für Landwirtschaft und Ernährung.

https://tgrdeu.genres.de/gefaehrdung/index

[8] Roughsedge, T., Brotherstone, S. and Visscher, P.M. (2017) Quantifying Genetic Contributions to a Dairy Cattle Population Using Pedigree Analysis. Livestock Science, 60, 359-369. https://doi.org/10.1016/S0301-6226(99)00106-2

[9] Koenig, S. and Simianer, H. (2006) Approaches to the Management of Inbreeding and Relationship in the German Holstein Dairy Cattle Population. Livestock Science, 103, 40-53. https://doi.org/10.1016/j.livsci.2005.12.009

[10] Mc Parland, S., Kearney, F. and Berry, D.P. (2009) Purging of Inbreeding Depression within the Irish Holstein-Friesian Population. Genetics Selection Evolution, 41, 16. https://doi.org/10.1186/1297-9686-41-16

[11] Mc Parland, S., Kearney, J.F., Rath, M. and Berry, D.P. (2007) Inbreeding Effects on Milk Production, Calving Performance, Fertility, and Conformation in Irish Holstein-Friesians. Journal of Dairy Science, 90, 4411-4419. https://doi.org/10.3168/jds.2007-0227

[12] Hinrichs, D. and Thaller, G. (2011) Pedigree Analysis and Inbreeding Effects on Calving Traits in Large Dairy Herds in Germany. Journal of Dairy Science, 94, 4726-4733. https://doi.org/10.3168/jds.2010-4100

[13] Hinrichs, D., Bennewitz, J., Wellmann, R. and Thaller, G. (2015) Estimation of Ancestral Inbreeding Effects on Stillbirth, Calving Ease and Birthweight in German Holstein Dairy Cattle. Journal of Animal Breeding and Genetics, 132, 59-67. https://doi.org/10.1111/jbg.12114

[14] Kalinowski, S.T., Hedrick, P.W. and Miller, P.S. (2000) Inbreeding Depression in the Speke's Gazelle Captive Breeding Program. Conservation Biology, 14, 13751384. https://doi.org/10.1046/j.1523-1739.2000.98209.x

[15] Ballou, J.D. (1997) Ancestral Inbreeding only Minimally Affects Inbreeding Depression in Mammalian Populations. Journal of Heredity, 88, 169-178.

https://doi.org/10.1093/oxfordjournals.jhered.a023085

[16] Baumung, R., Farkas, J., Boichard, D., Mészáros, G., Sölkner, J. and Curik, I. (2015) GRAIN: A Computer Program to Calculate Ancestral and Partial Inbreeding Coefficients Using a Gene Dropping Approach. Journal of Animal Breeding and Genetics, 132, 100-108. https://doi.org/10.1111/jbg.12145

[17] MacCluer, J.W., Boyce, A.J., Dyke, B., Weitkamp, L.R., Pfenning, D.W. and Par- 
sons, C.J. (1983) Inbreeding and Pedigree Structure in Standardbred Horses. Journal of Heredity, 74, 394-399. https://doi.org/10.1093/oxfordjournals.jhered.a109824

[18] Maignel, L., Boichard, D. and Verrier, E. (1996) Genetic Variability of French Dairy Breeds Estimated from Pedigree Information. Interbull Bulletin, 14, 49.

[19] Boichard, D. (2002) PEDIG: A Fortran Package for Pedigree Analysis Suited for Large Populations. Proceedings of the 7 th World Congress on Genetics Applied to Livestock Production, 32, 525-528.

[20] Cheng, R., Abney, M., Palmer, A.A. and Skol, A.D. (2011) QTLRel: An R Package for Genome-Wide Association Studies in Which Relatedness is a Concern. BMC Genetics, 12, 66. https://doi.org/10.1186/1471-2156-12-66

[21] Gutiérrez, J.P. and Goyache, F. (2005) A Note on ENDOG: A Computer Program for Analysing Pedigree Information. Journal of Animal Breeding and Genetics, 122, 172-176. https://doi.org/10.1111/j.1439-0388.2005.00512.x

[22] Meuwissen, T.H.E. and Luo, Z. (1992) Computing Inbreeding Coefficients in Large Populations. Genetics Selection Evolution, 24, 305. https://doi.org/10.1186/1297-9686-24-4-305

[23] MacCluer, J.W., VandeBerg, J.L., Read, B. and Ryder, O.A. (1986) Pedigree Analysis by Computer Simulation. Zoo Biology, 5, 147-160. https://doi.org/10.1002/zoo.1430050209

[24] Suwanlee, S., Baummung, R., Solkner, J. and Curik, I. (2007) Evaluation of Ancestral Inbreeding Coefficients: Ballou's Formula versus Gene Dropping. Conservation Genetics, 8, 489-495. https://doi.org/10.1007/s10592-006-9187-9

[25] Falconer, D.S. and Mackay, T.F. (1996) Introduction to Quantitative Genetics. 4th Edition, Prentice Hall, Essex.

[26] Lacy, R.C. (1989) Analysis of Founder Representation in Pedigrees: Founder Equivalents and Founder Genome Equivalents. Zoo Biology, 8, 111-123.

https://doi.org/10.1002/zoo.1430080203

[27] Boichard, D., Maignel, L. and Verrier, E. (1997) The Value of Using Probabilities of Gene Origin to Measure Genetic Variability in a Population. Genetics Selection Evolution, 29, 5. https://doi.org/10.1186/1297-9686-29-1-5

[28] Bernardes, P.A., et al. (2016) Population Structure of Tabapuã Beef Cattle Using Pedigree Analysis. Livestock Science, 187, 96-101.

[29] Hazuchová, E., Kadlečík, O., Pavlík, I. and Kasarda, R. (2013) Assessment of Genetic Diversity Using Characteristics Based on Probability of Gene Origin in Slovak Spotted Breed. Acta Fytotechnica et Zootechnica, 16, 2.

[30] Kehr, C., Klunker, M., Fischer, R., Groeneveld, E. and Bergfeld, U. (2010) Untersuchungen $\mathrm{zu}$ einem Monitoring genetischer Diversität bei Nutztierrassen: Ergebnisse zum Roten Höhenvieh. Züchtungskunde, 82, 387-399.

[31] FAO (1998) Secondary Guidelines for Development of National Farm Animal Genetic Resources Management Plans-Management of Small Populations at Risk. Rome. http://www.fao.org/3/a-w9361e.pdf

[32] Meuwissen, T.H.E. and Woolliams, J.A. (1994) Effective Sizes of Livestock Populations to Prevent a Decline in Fitness. Theoretical and Applied Genetics, 89, 1019 1026.

[33] Melka, M.G., Stachowicz, K., Miglior, F. and Schenkel, F.S. (2013) Analyses of Genetic Diversity in Five Canadian Dairy Breeds Using Pedigree Data. Journal of Animal Breeding and Genetics, 130, 476-486. https://doi.org/10.1111/jbg.12050 
[34] Marquez, G.C., Speidel, S.E., Enns, R.M. and Garrick, D.J. (2010) Genetic Diversity and Population Structure of American Red Angus Cattle. Journal of Animal Science, 88, 59-68. https://doi.org/10.2527/jas.2008-1292

Submit or recommend next manuscript to SCIRP and we will provide best service for you:

Accepting pre-submission inquiries through Email, Facebook, LinkedIn, Twitter, etc. A wide selection of journals (inclusive of 9 subjects, more than 200 journals)

Providing 24-hour high-quality service

User-friendly online submission system

Fair and swift peer-review system

Efficient typesetting and proofreading procedure

Display of the result of downloads and visits, as well as the number of cited articles Maximum dissemination of your research work

Submit your manuscript at: http://papersubmission.scirp.org/

Or contact as@scirp.org 